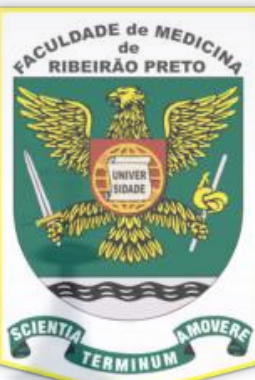

\title{
ASYMPTOMATIC CAROTID STENOSIS, WHITE MATTER DISEASE AND COGNITION: CONTRIBUTIONS TO A CLINICAL PROFILE
}

\author{
Ana Paula Afonso Camargo-Ferreira ${ }^{1}$, Pedro Henrique R. Silva ${ }^{2}$, Antonio Carlos Senra Filho ${ }^{2}$ \\ Guilherme Riccioppo Rodrigues ${ }^{1}$, Leticia Januzi ${ }^{1}$, Renata F. Leoni ${ }^{2}$, Octavio M. Pontes-Neto ${ }^{1}$ \\ Department of Neuroscience and Behavioral Sciences - Ribeirao Preto School of Medicine ${ }^{1}$
} Inbrain Lab, Department of Physics, FFCLRP2

University of São Paulo

\section{Background and Purpose}

Patients with carotid stenosis, without history of stroke or transient ischemic attack are considered to be asymptomatic. However, many of those patients might have high burden of white matter hyperintensities (WMH) and cognitive decline that may precede clinical events, suggesting a high risk for stroke. In the present study, we aimed to assess the association between asymptomatic carotid stenosis, WMH and cognitive decline.

\section{Methods}

Participants were evaluated with 3T MRI using T2- weighted FLAIR for quantification of $\mathrm{WMH}$ and $\mathrm{WM}$ volume. Lesion segmentation was performed by the SPM-12 using an automatic algorithm. Continuous variables were tested for normality using Shapiro-Wilk normality test. Unpaired t-test and Mann-Whitney $U$ test were used for to analyze group differences. Pearson correlation coefficient was used to explore associations among scores of neuropsychological tests and burden of WMH between groups. Hemispheric differences in WM and burden of WMH were tested for Paired t-test. A $p<0.05$ was considered significant. Statistical analyses were performed using Stata 15.

\begin{tabular}{|c|c|c|c|}
\hline & Patients ( $n=13$ ) & Controls ( $n=13$ ) & $p$ value \\
\hline Age (years) & $69,46 \pm 7,60$ & $62,23 \pm 6,82$ & 0,051 \\
\hline Female: Male (female \%) & $7: 6(53,84)$ & $6: 7(46,15)$ & 0,708 \\
\hline Education (years) & $8,23 \pm 6,64$ & $10,76 \pm 5,40$ & 0,296 \\
\hline \multicolumn{4}{|c|}{ Diagnosis } \\
\hline Stenotic side ( $>70 \% / \mathrm{n}$ patients) & esquerda:7; direita: 6 & $\mathrm{~N} / \mathrm{A}$ & $\mathrm{N} / \mathrm{A}$ \\
\hline Stenosis unilateral/ bilateral $(\mathrm{n})$ & $7: 6$ & $\mathrm{~N} / \mathrm{A}$ & $\mathrm{N} / \mathrm{A}$ \\
\hline \multicolumn{4}{|c|}{ Cognitive Assessment } \\
\hline Mini Mental Status Examination $1^{\text {st }}$ ed & $25,76 \pm 2,83$ & $26,76 \pm 3,26$ & 0,412 \\
\hline Symbol Digit (MMSE-2) & $6,23 \pm 2,16$ & $13,92 \pm 5,25$ & $<0,001$ \\
\hline \multicolumn{4}{|l|}{ Memory/ Visuospacial Perception } \\
\hline Rey Complex Figure Test (immediate) & $-2,00 \pm 1,45$ & $-0,75 \pm 1,30$ & 0,030 \\
\hline Digit Span (direct order) & $-0,45 \pm 0,96$ & $0,95 \pm 1,50$ & 0,008 \\
\hline \multicolumn{4}{|l|}{ Executive Functions } \\
\hline Stroop Test 2 & $-3,86 \pm 2,58$ & $-1,91 \pm 1,72$ & 0,017 \\
\hline Stroop Test 3 & $-1,52 \pm 1,82$ & $-0,30 \pm 0,86$ & 0,039 \\
\hline Trail Making Test A & $-3,73 \pm 2,76$ & $-1,23 \pm 1,94$ & 0,013 \\
\hline Digit Span (inverse order) & $-0,47 \pm 0,73$ & $0,89 \pm 1,06$ & 0,015 \\
\hline Verbal Fluency (phonemic) & $-0,96 \pm 0,56$ & $-0,26 \pm 0,91$ & 0,028 \\
\hline
\end{tabular}

Table 1. Basic demographic, diagnosis and cognitive assessment of healthy controls and patients with symptomatic carotid stenosis

\section{Results}

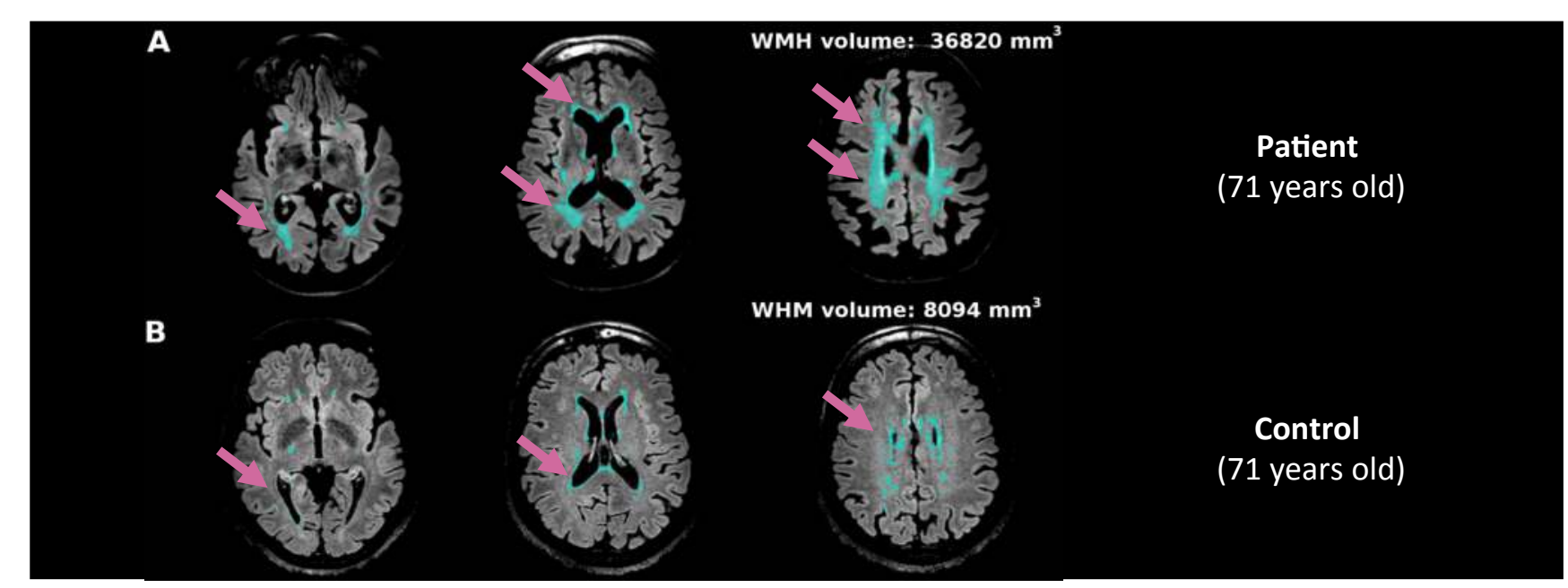

Figure 1. Segmentation of White Matter Hyperintensities mensuread by FLAIR in patient with asymptomatic carotid stenosis and control. In both subjects, WMH are countered in green, by using an automatic algorithm.

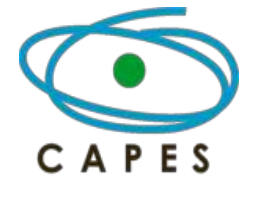

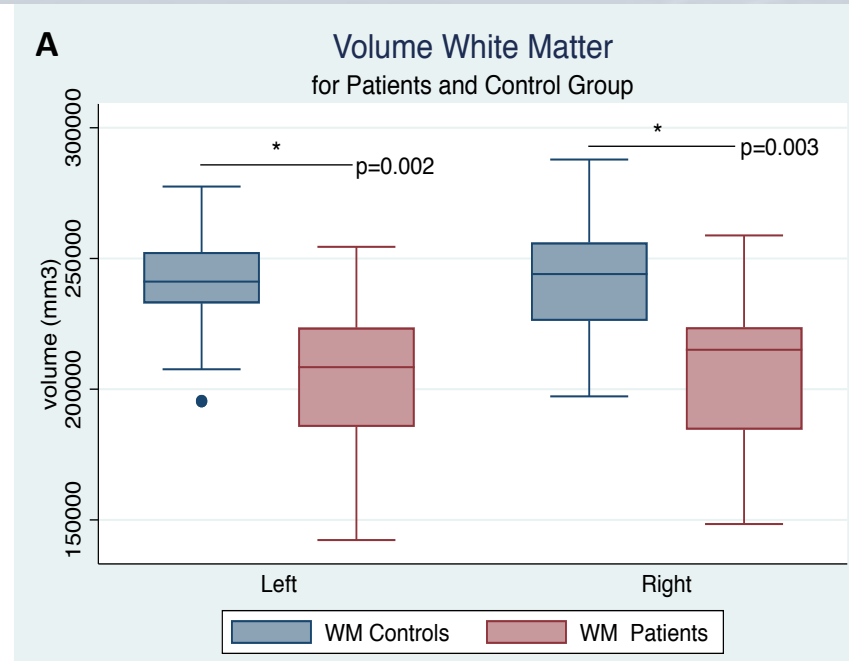
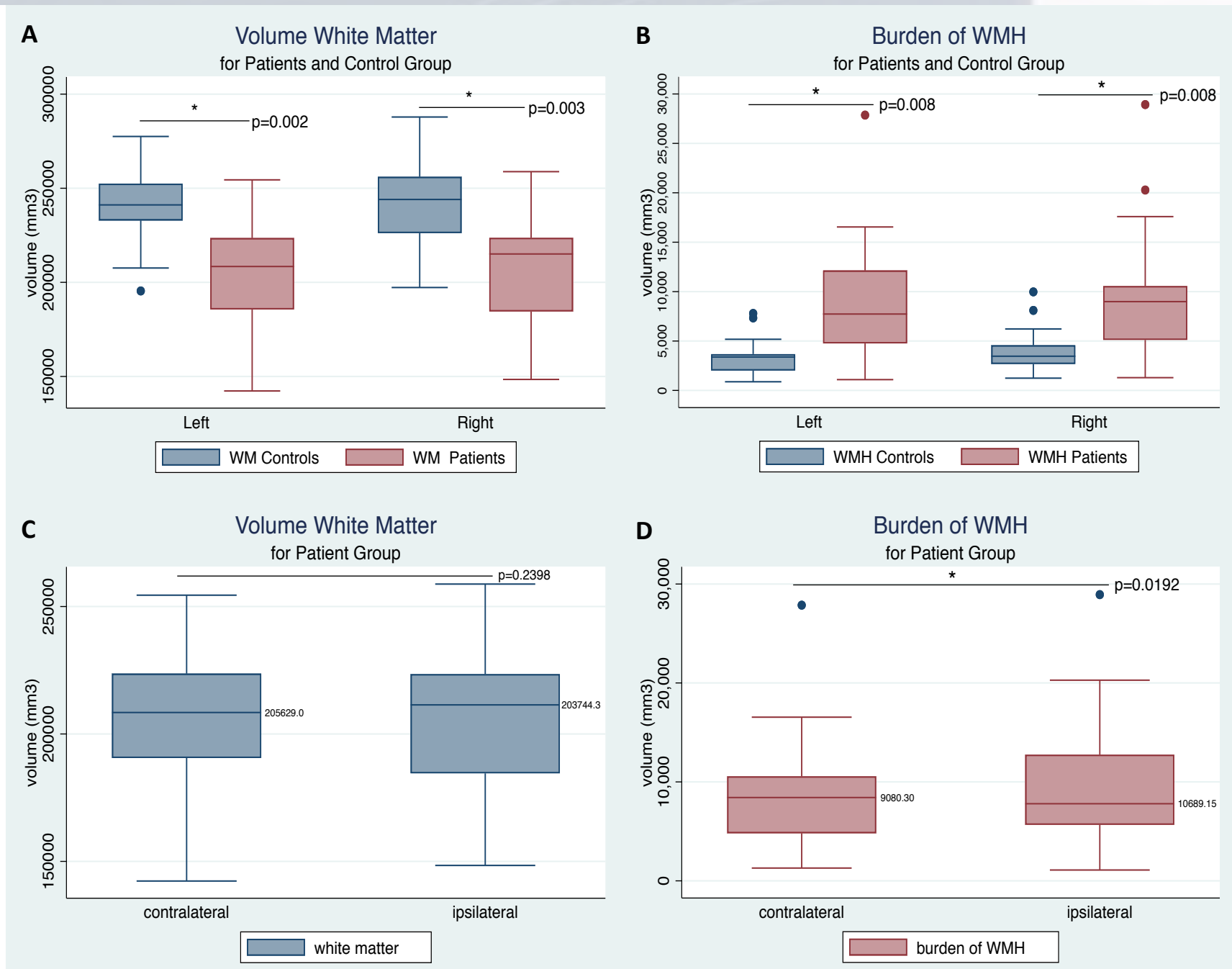

Figure 2. Box plot showing the significant differences the white matter volume (Panel A) and white matte hyperintensities (Panel B) between groups. Panels C and D show hemispheric differences in WM and burden of WMH for patients with asymptomatic carotid stenosis.

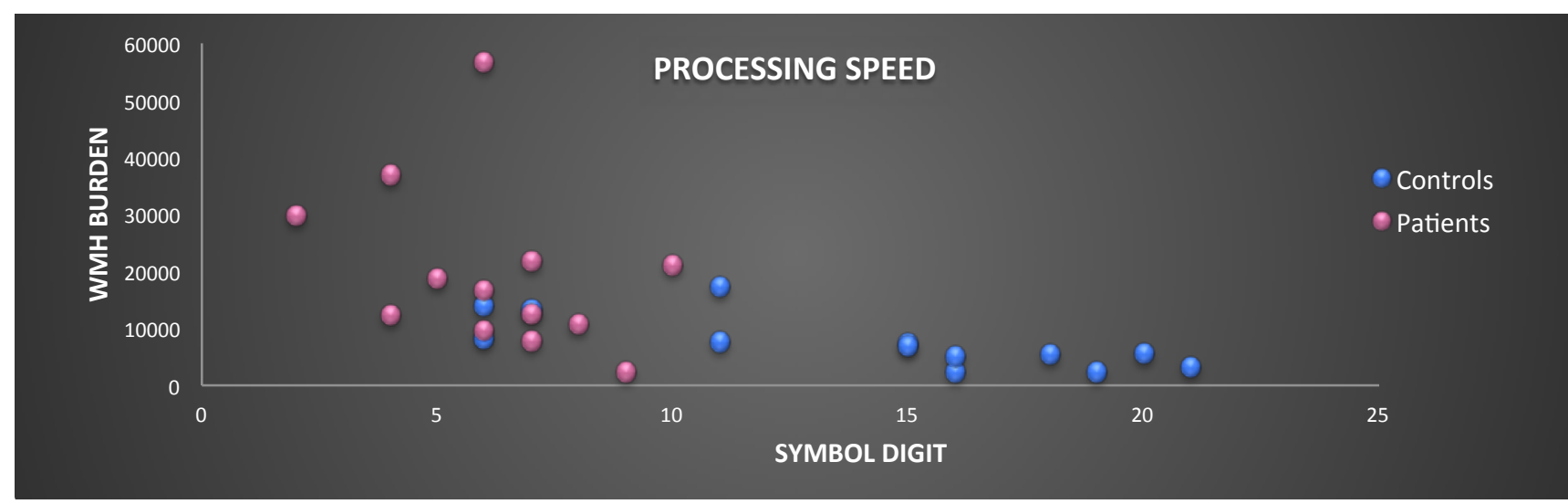

Figure 3. Scatter plot of the correlation analyses between burden of WMH and cognitive performance in Symbol Digit.

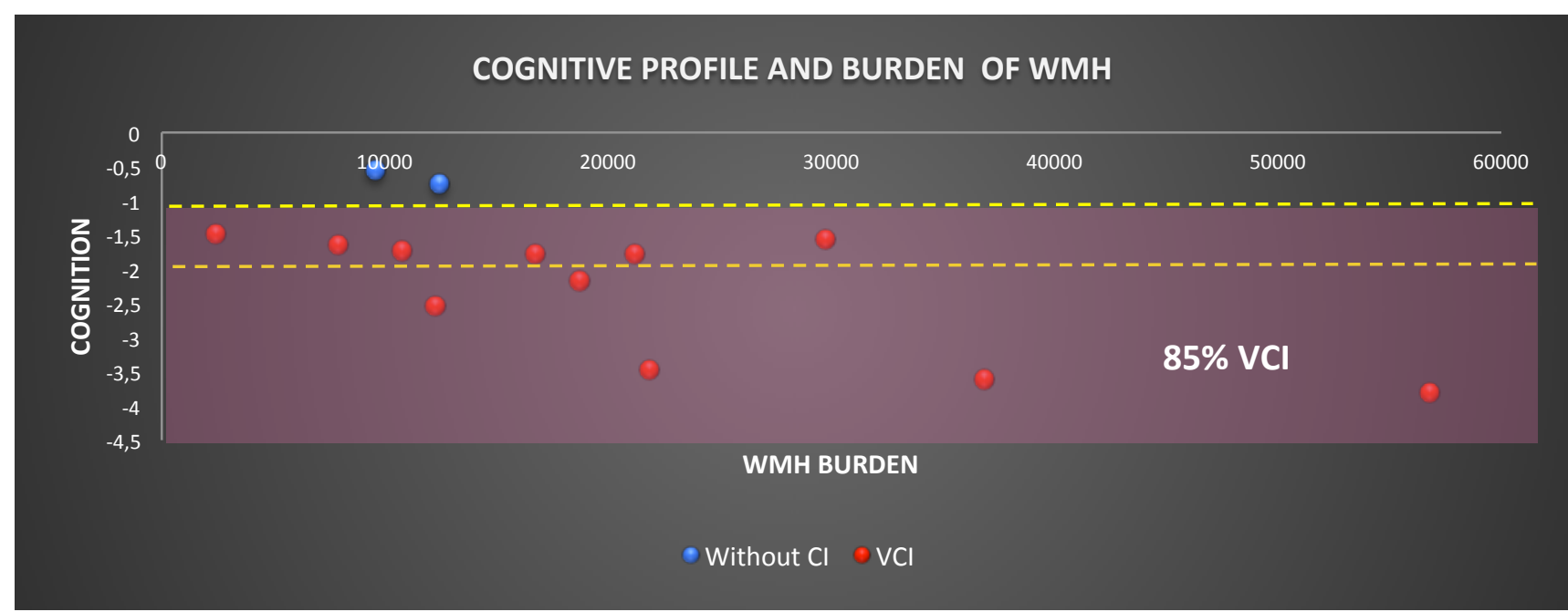

Figure 4. Scatter plot of the correlation analyses between burden of WMH and global cognitive performance for clinical group. Dashed line between z-score -1 and -2 indicates mild cognitive impairmen and below -2 possible dementia. $\mathrm{Cl}$, Cognitive impairments; $\mathrm{VCl}$, Vascular cognitive impairments.

\section{Conclusions}

Vascular cognitive decline and high burden of white matter hyperintensities are common in patients with asymptomatic carotic stenosis $>70 \%$ and should be explored as markers of high risk of stroke in those patients. In addition, the results of the present study, acquired with a carefully selected sample, demonstrated a larger WMH burden in the hemisphere ipsilateral to carotid stenosis, suggesting an important role of hypoperfusion in white matter microstructural damage and small vessel disease.

\section{References}

Ammirati, E. et al. Relation between characteristics of carotid atherosclerotic plaques and brain white matter hyperintensities in asymptomatic patients. Scientific Reports, 7: 10559, 2017.

Prabhakaran S. Imaging markers of stroke risk in asymptomatic carotid stenosis. Brain Circ 1:38 $46,2015$. Debette, S. et al. The clinical importance of white matter hyperintensities on brain magnetic resonance imaging. systematic review and meta-analysis. BML, 341. $3666,2010$. 